\title{
Obtenção e uso das plantas medicinais no distrito de Martim Francisco, Município de Mogi-Mirim, SP, Brasil
}

\author{
Milena Andrea Curitiba Pilla ${ }^{1,4}$, Maria Christina de Mello Amorozo ${ }^{2}$ e Antonio Furlan ${ }^{3}$
}

Recebido em 26/01/2005. Aceito em 27/04/2006

\begin{abstract}
RESUMO - (Obtenção e uso das plantas medicinais no distrito de Martim Francisco, Município de Mogi-Mirim, SP, Brasil). O objetivo do presente trabalho foi realizar um inventário das plantas medicinais conhecidas e usadas pela população do distrito de Martim Francisco, Município de Mogi-Mirim, SP, bem como conhecer seus empregos e sua importância na comunidade. Foram amostradas aleatoriamente 50 unidades domiciliares. Apenas um dos adultos responsáveis pela casa (homem ou mulher) foi entrevistado, através de questionários. As plantas citadas foram coletadas e fotografadas paralelamente à aplicação dos questionários. O material botânico foi identificado e depositado no Herbarium Rioclarense (HRCB). Ao todo, foram catalogadas 107 espécies botânicas, predominantemente herbáceas e cultivadas, distribuídas em 40 famílias, sendo as famílias Lamiaceae e Asteraceae as mais representativas. Os índices de diversidade $\left(\mathrm{H}^{\prime}=4,07\right.$; e = 0,87) foram altos, se comparados aos obtidos em outros trabalhos no interior do Estado de São Paulo. Na preparação dos remédios, as folhas foram a parte da planta mais utilizada e a decocção a principal forma de preparo. A via oral foi a mais empregada para a administração dos medicamentos e as doenças mais freqüentemente tratadas por remédios caseiros referem-se aos Sistemas Digestivo e Respiratório. Não existe um rigor na posologia e na duração do tratamento, ficando este a critério do hábito de cada pessoa entrevistada. As plantas que apresentaram índice de importância relativa e concordância de uso acima de $60 \%$ foram: boldo (Plectranthus barbatus Andrews), capim-santo (Cymbopogon citratus (DC) Stapf), hortelã (Mentha sp. 2) e poejo (Cunila microcephala Benth.).
\end{abstract}

Palavras-chave: etnobotânica, plantas medicinais, medicina popular

\begin{abstract}
Acquisition and use of medicinal plants in Martim Francisco district, Mogi Mirim Municipality, São Paulo State, Brazil). The aim of this work was to do an ethnobotanical survey of medicinal plants known and used by people in the Martim Francisco district, Mogi Mirim Municipality, São Paulo State, Brazil, as well as to investigate their application and importance for the community. A questionnaire was applied to a random sample of 50 households; in each, one adult (male or female) was interviewed. Plants cited were collected and photographed in conjunction with the interview; they were then identified and deposited at the Herbarium Rioclarense (HRCB). The 107 species were mainly cultivated herbs belonging to 40 botanical families; Lamiaceae and Asteraceae were the most representative. Diversity indexes $\left(H^{\prime}=4.07 ; \mathrm{e}=0.87\right)$ were high when compared to surveys in other localities of São Paulo State. Leaves were the plant parts most utilized and decoction the most common way of preparation. Plant remedies were generally taken orally, and used to treat digestive and respiratory systems ailments. Dosage and treatment duration were rather loosely defined. Plants presenting relative importance and use agreement above 60\% were as follows: "boldo" (Plectranthus barbatus Andrews), "capim-santo" (Cymbopogon citrates (DC) Stapf), mint (Mentha sp. 2) and "poejo" (Cunila microcephala Benth.).
\end{abstract}

Key words: ethnobotany, medicinal plants, folk medicine

\section{Introdução}

Com maior freqüência, as pesquisas etnobotânicas além de abordarem populações tradicionais, como indígenas e caiçaras, também se concentram em populações de cidades (Castellucci et al. 2001; Marodin \& Baptista 2001; Dorigoni et al. 2001) e de pequenos núcleos urbanos com origem rural (SilvaAlmeida \& Amorozo 1998; Garlet \& Irgang 2001; Silva \& Andrade 2005). Nestas populações, tem sido observada a utilização das plantas como um dos poucos recursos terapêuticos para tratar suas doenças mais freqüentes.

Apesar do sistema de saúde oficial gratuito atualmente estender-se à zona rural, ele não consegue atender de forma adequada à demanda e estas populações não têm poder aquisitivo suficiente para pagar um profissional de saúde. Além disso, medicamentos industrializados são caros e as pessoas se rendem à facilidade de se obter as plantas

\footnotetext{
1 Av. Juscelino K. de Oliveira 350, casa 30, Jardim América, 13806-520 Mogi-Mirim, SP, Brasil

2 Universidade Estadual Paulista "Julio de Mesquita Filho, Departamento de Ecologia, C. Postal 199, 13506-900 Rio Claro, SP, Brasil

3 Universidade Estadual Paulista "Julio de Mesquita Filho, Departamento de Botânica, C. Postal 199, 13506-900 Rio Claro, SP, Brasil

4 Autor para correspondência: milenapilla@htomail.com
} 
medicinais, que muitas vezes são cultivadas nos quintais de suas casas.

Em geral, estas comunidades possuem conhecimento básico do uso de plantas medicinais e estas informações são trocadas entre os indivíduos num processo dinâmico de aquisição e perda (Amorozo 2002). No entanto, à medida que a relação com a terra se transforma pela modernização do campo e o contato com a sociedade nacional se intensifica, seja pelos meios de comunicação ou por agentes sociais, a rede de transmissão do conhecimento sobre plantas pode sofrer alterações.

Portanto, resgatar este conhecimento e suas técnicas terapêuticas é uma maneira de deixar registrado um modo de aprendizado informal que contribui para a valorização da medicina popular, além de gerar informações sobre a saúde da comunidade local.

O objetivo do presente trabalho foi realizar o levantamento das espécies de plantas medicinais conhecidas e usadas pela população do distrito de Martim Francisco, Município de Mogi-Mirim, SP, bem como conhecer a finalidade do uso, parte da planta utilizada, modo de preparo dos remédios, juntamente com a posologia e fonte de obtenção das plantas citadas. Foi também avaliar o grau de importância destas plantas na comunidade por meio da análise de diversidade e da frequiência de citação e concordância quanto aos usos principais e comparar a outras localidades.

\section{Material e métodos}

Área de Estudo - O distrito de Martim Francisco pertence a Mogi-Mirim, distante $8 \mathrm{~km}$ da sede do município e tem divisa com os Municípios de Itapira e Santo Antônio de Posse.

Mogi-Mirim é um Município do interior paulista, localizado a $632 \mathrm{~m}$ acima do nível do mar, situado na base da Serra da Mantiqueira, com vegetação basicamente de cerrado. Possui uma área territorial de $499 \mathrm{~km}^{2}$. Sua latitude é de $22^{\circ} 43^{\prime} 19^{\prime}$ 'S e longitude de 46 $95^{\circ}$ '77' 'W. Está distante da capital de São Paulo $160 \mathrm{~km}$. A via de acesso ao distrito é próxima a uma Zona de Proteção Ambiental, composta por fragmentos de Mata Atlântica e Cerrado.

Martim Francisco teve origem no final do século XIX, quando a Companhia Mogiana de Estrada de Ferro comprou uma gleba de terras, com a finalidade de instalar a Estação Ferroviária. A Companhia transportava madeira, gado e passageiros, atraindo investimentos e emprego. Hoje, a linha férrea limita-se ao transporte de carga.

O distrito começou a crescer na década de 1960, após o estabelecimento da cultura da cana-de-açúcar e a instalação de uma usina de açúcar e aguardente. A partir da década de 1980, a fabricação de aguardente foi substituída pela produção de combustível para automóveis (programa Pró-Álcool). Os holandeses e descendentes, que são conhecidos pela grande representatividade no comércio de flores e plantas ornamentais no Brasil e no exterior, compraram boa parte das terras que compõem o distrito, incluindo as da usina, para cultivar flores (rosas, crisântemos, espatifilos etc.).

Atualmente, as principais atividades econômicas do distrito estão voltadas à produção de flores (rosas e crisântemos), suinocultura, cultura de laranja, cana-deaçúcar e abacate, além do pequeno comércio existente na região, insuficiente para absorver toda a mão-deobra local. Martim Francisco possui 2.991 habitantes: 1.569 homens e 1.422 mulheres, distribuídos em 540 residências (IBGE 2000). Dois bairros compõem o distrito, um mais antigo, Martim Francisco propriamente dito, e outro criado há cerca de cinco anos, denominado Jardim Mandaia, com lotes de tamanhos menores.

As ruas são pavimentadas, com instalação de sistema de esgoto, de água, telefonia e iluminação. São fornecidos à população serviços urbanos, como transportes coletivos, educação (Escolas de Ensino Fundamental e Creches) e saúde (Posto de Saúde, instalado em dezembro/1988).

A unidade de saúde funciona de segunda a sextafeira. $\mathrm{O}$ atendimento médico ocorre ora no período da manhã, ora no período da tarde, com as seguintes especialidades: Ginecologia, Pediatria e Clínica Geral. Consultas com Fonoaudiólogos, Psicólogos e Dentistas também estão disponíveis à população do distrito.

A distribuição de medicamentos ocorre somente sob prescrição médica e é efetuada pela enfermeira responsável. Geralmente, são antibióticos, remédios para os sistemas digestivo e respiratório, além de vacinas e materiais para curativo de ferimentos.

Metodologia - Os dados foram coletados no período de fevereiro a julho/2002, por meio de questionários testados previamente.

Através de mapas, foram sorteadas 50 unidades domiciliares, ou seja, 9,26\% do total de domicílios de Martim Francisco, onde um indivíduo adulto responsável (homem ou mulher) foi entrevistado. Em caso de recusa à participação, o domicílio do lado direito foi incluído na amostra. A entrevista foi feita 
seguindo o pré-requisito básico: as pessoas utilizarem plantas para fins terapêuticos. Foram catalogadas as plantas conhecidas e aquelas realmente utilizadas pela comunidade. As plantas citadas foram coletadas junto com os informantes, percorrendo os quintais dos domicílios ou visitando os vizinhos de quem se obtinham plantas medicinais. Estas foram identificadas por taxonomistas e por meio de literatura e depositadas no Herbarium Rioclarense (HRCB).

Para a análise, foram utilizadas medidas comumente empregadas em Ecologia e adaptadas por Begossi (1996), tais como o índice de diversidade de Shannon-Wiener e de equiidade de Pielou, respectivamente,

$$
\mathrm{H}^{\prime}=- \text { pi } \sum \log \mathrm{pi} \text {, }
$$

onde, $\mathrm{pi}=\mathrm{ni} / \mathrm{N}$, sendo, $\mathrm{ni}=\mathrm{n}^{\circ}$ de citações por espécie; $\mathrm{N}=$ número total de citações.

$$
\mathrm{e}=\mathrm{H}^{\prime} / \log \mathrm{S} \text {, }
$$

onde, $\mathrm{H}^{\prime}=$ índice de Shannon-Wiener; $\mathrm{S}=$ riqueza de espécies.

A curva de rarefação foi calculada para se verificar a suficiência amostral, através do programa Krebs para MS-DOS (Krebs 1989), levando-se em conta o número de citações por espécie, considerando apenas uma citação de uso por informante por planta.

A porcentagem de concordância quanto aos usos principais (CUP) foi calculada para se determinar a importância relativa das espécies citadas na comunidade. Seu cálculo foi determinado baseandose em Amorozo \& Gély (1988), modificado de Friedman et al. (1986):

$$
\mathrm{CUP}=(\mathrm{ICUP} / \mathrm{ICUE}) \times 100
$$

onde, ICUP $=\mathrm{n}$. de informantes que citaram os usos principais; ICUE $=\mathrm{n}$. de informantes que citaram $\mathrm{o}$ uso da espécie.

$\mathrm{O}$ valor encontrado foi multiplicado por um fator de correção que leva em conta a freqüência de citação de cada espécie em relação à da espécie mais citada.

$$
\mathrm{FC}=\text { ICUE / espécie mais citada }
$$

Desta forma, a CUP corrigida é determinada pela seguinte equação:

$$
\mathrm{CUPc}=\mathrm{CUP} \times \mathrm{FC}
$$

Para verificar se havia correlação entre o número de plantas conhecidas e o número de plantas utilizadas, empregou-se o coeficiente de correlação de Kendall (tau); para avaliar diferenças no conhecimento e uso de plantas com relação à idade, foi aplicado o teste $\mathrm{U}$ de Mann-Whitney (Ayres et al. 2006; Siegel 1975).

Os dados sócio-econômicos foram descritos e o resultado sobre o rendimento mensal foi comparado com dados do IBGE (2000).

\section{Resultados e discussão}

Caracterização sócio-econômica dos entrevistados No presente estudo, todos os indivíduos abordados $(n=50)$ faziam uso de plantas medicinais para curar suas doenças mais freqüentes. Houve $10 \%$ de substituição da amostra original, porém não relacionada ao fato da não utilização das plantas. Dos entrevistados, $60 \%$ têm 40 anos ou mais; $88 \%$ são mulheres, com uma variação de idade entre 21 e 69 anos.

Do total de mulheres entrevistadas $(n=44), 56,8 \%$ são donas de casa e 18,2\% trabalham no comércio local ou em Mogi-Mirim. Das demais, 11,4\% trabalham como domésticas em residências da comunidade, $9 \%$ prestam serviços rurais (na colheita, em emprego temporário) e 4,6\% são aposentadas ou pensionistas. Dos homens entrevistados $(n=6), 67 \%$ desempenham atividades remuneradas no setor de serviços e comércio e $33 \%$ são aposentados.

Os indivíduos nascidos em Mogi-Mirim representam 34\% da amostra. Outros 36\% vieram de outros municípios do Estado de São Paulo e o restante procede de diversos Estados do Brasil, como Minas Gerais, Ceará, Pernambuco, Bahia e Rio Grande do Sul. Dos entrevistados, $78 \%$ são da zona rural, sendo todos os nativos do município de origem rural.

Quanto à escolaridade, 66\% não completaram o Ensino Fundamental, sendo que a maioria destes não completou a $4^{\text {a }}$ série; $24 \%$ têm entre 8 e 11 anos de escolaridade; e cerca de $10 \%$ não freqüentaram a escola. De um modo geral, o grau de escolaridade não foi fator de influência no uso de plantas medicinais, pois os diferentes informantes demonstraram conhecimentos semelhantes tanto de uso quanto de tratamento.

$\mathrm{O}$ rendimento médio mensal familiar concentrase principalmente nas faixas entre mais de dois a cinco salários mínimos (54\% da população amostrada) e mais de cinco a dez salários mínimos (26\%). A porcentagem de famílias com rendimentos abaixo e acima destas faixas é bem inferior à da região sudeste como um todo (IBGE 2000).

A maior parte possui casa própria; somente $4 \%$ dos entrevistados moram em casa alugada. A questão referente à posse da casa não se mostra relevante, 
pois a maioria dos informantes no Jardim Mandaia possui casa própria, contudo o cultivo de plantas é limitado em função do pouco tempo de residência no local, caso este não observado no bairro antigo do distrito. Muitos entrevistados obtêm plantas medicinais de seus parentes, vizinhos e das proximidades de suas casas (plantas espontâneas, ruderais).

Quanto à religião, parcela significativa dos informantes é católica (92\%). Freqüentemente fazem referências à Igreja no preparo dos remédios caseiros, cujas receitas e até mesmo algumas plantas são obtidas com a Pastoral da Saúde e com o Padre da paróquia.

Dados botânicos e ecológicos das plantas - Em 50 entrevistas, foram obtidas 516 citações relativas a 107 espécies distribuídas em 40 famílias. Treze plantas não puderam ser identificadas. Apenas oito entrevistados utilizam todas as plantas que citaram.

Dentre as famílias botânicas, as que tiveram maior número de espécies foram Lamiaceae, compreendendo 14 espécies e Asteraceae, com 12 espécies citadas (Fig. 1). O mesmo foi observado em trabalhos realizados em localidades do interior paulista: A.P.G. Savassi (dados não publicados); Silva-Almeida \& Amorozo (1998); E.F.P.E. Gama (dados não publicados), todos no Município de Rio Claro, SP; Castellucci et al. (2000) no Município de Luis Antonio, SP; F.M. Scarda (dados não publicados) no Município de Itu, SP. No Rio Grande do Sul (Dorigoni et al. 2001; Garlet \& Irgang 2001) e em comunidades caiçaras do litoral paulista (Di Stasi et al. 2002; Hanazaki et al. 2000), os trabalhos também apontam o predomínio destas famílias no que se refere a plantas medicinais.

Os entrevistados utilizam, em média, 65\% das plantas que citaram. Dentre as espécies citadas, a maioria apresenta hábito herbáceo (57\%), seguido de arbóreo $(21 \%)$ e arbustivo (15\%); as plantas são

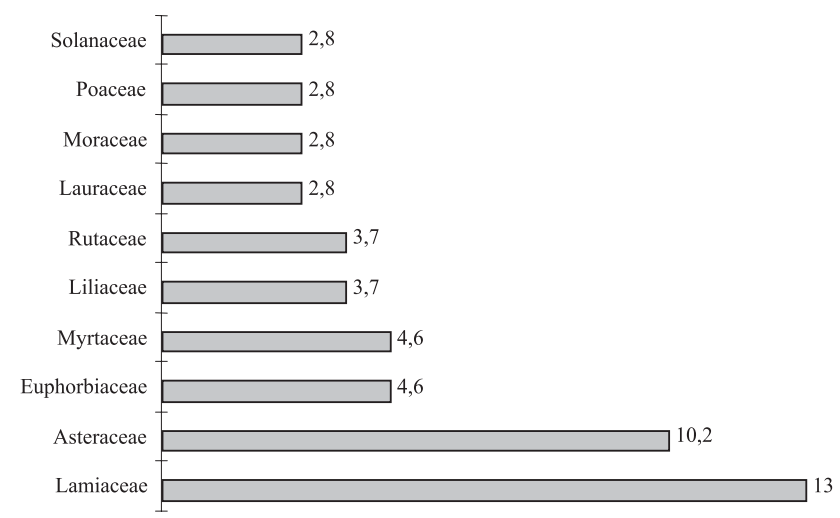

Figura 1. Famílias botânicas representadas por três ou mais espécies $(\%)$. predominantemente cultivadas $(80,4 \%)$, sendo que algumas espontâneas também são cultivadas. Quanto à obtenção dos recursos vegetais, $54 \%$ das espécies são provenientes do cultivo caseiro (Fig. 2).

A predominância do hábito herbáceo também foi observada em outros trabalhos no Estado de São Paulo (A.P.G. Savassi, dados não publicados; F.M. Scarda, dados não publicados; Silva-Almeida \& Amorozo 1998; E.F.P.E. Gama, dados não publicados). A predominância de ervas na composição dos remédios caseiros pode estar relacionada ao fato de serem cultivadas geralmente nos quintais, o que facilita a obtenção destes recursos vegetais.

O índice de diversidade de Shannon-Wiener em Martim Francisco é de 4,07 (Base e); e a eqüitabilidade é de 0,87 . Estes valores são próximos aos de outras localidades rurais do interior paulista (A.P.G. Savassi, dados não publicados; F.M. Scarda, dados não publicados; Silva-Almeida \& Amorozo 1998). Porém, em dois bairros da cidade de Rio Claro, SP (E.F.P.E. Gama, dados não publicados), a diversidade de espécies utilizadas foi menor quando comparada à da zona rural, mesmo tendo o número de informantes semelhante ao dos demais trabalhos.

A curva de rarefação do distrito de Martim Francisco mostra que o esforço amostral para Martim Francisco foi satisfatório (Fig. 3).

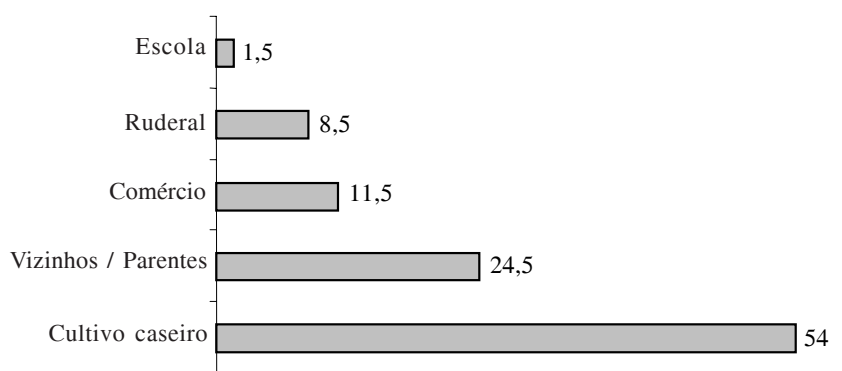

Figura 2. Fonte de obtenção de plantas medicinais (\%).

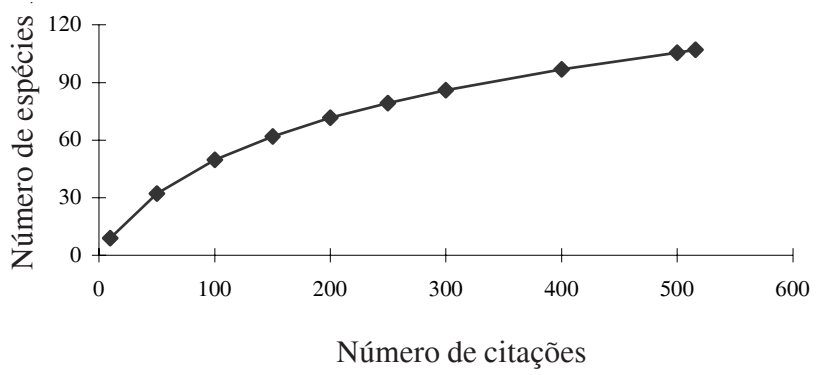

Figura 3. Curva de rarefação obtida em Martim Francisco. $(-\bullet-=\mathrm{MF})$. 
Os índices obtidos no distrito de Martim Francisco mostram-se relativamente baixos ao serem comparados aos de localidades habitadas por populações tradicionais em regiões com rica flora nativa (Amorozo 2002; Pake 1987 apud Begossi 1996) (Tab. 1). Nestas áreas, a diversidade de espécies utilizadas foi maior, refletindo tanto a disponibilidade de recursos vegetais, quanto a familiaridade da população com estes recursos.

Dados da utilização medicinal das plantas - A Tab. 2 traz a relação de plantas levantadas no distrito de Martim Francisco. As plantas mais citadas no presente trabalho são também as mais usadas. Dentre elas, está o boldo (Plectranthus barbatus Andrews) com 35 citações, sendo que $71 \%$ dos que citaram utilizam-no para afeções do sistema digestivo. Em segundo lugar, o capim-santo (Cymbopogon citratus (D.C.) Stapf) com 32 citações e $75 \%$ das pessoas afirmando que o utilizam para doenças relacionadas com os Sistemas Nervoso e Respiratório. Em seguida está a hortelã (Mentha sp. 2) que apresenta 30 citações, sendo que 90\% das pessoas a utilizam, principalmente, para doenças relacionadas a parasitas e dores de barriga. Cerca de $24 \%$ das espécies citadas não tinham sido utilizadas pelos entrevistados.

A parte da planta mais comumente empregada foi a folha $(57 \%)$, seguida do ramo e do fruto com menos de $20 \%$ de citações. A utilização de folhas tem sido freqüentemente citada em levantamentos no estado de São Paulo (A.P.G. Savassi, dados não publicados; Dias 1999; F.M. Scarda, dados não publicados; SilvaAlmeida \& Amorozo 1998; Gama 1997; A.S. Frias, dados não publicados) e no Rio Grande do Sul (Garlet \& Irgang 2001; Marodin \& Baptista 2001). O uso acentuado de folhas apresenta um caráter de conservação do recurso vegetal, pois não impede o desenvolvimento e a reprodução da planta, se a retirada da parte aérea não for excessiva (Martin 1995).

A decocção foi a principal forma de preparo dos medicamentos (Fig. 4). A mistura de plantas no preparo dos medicamentos é um hábito frequiente entre os informantes, porém, esta prática inspira cuidados, pois pode trazer efeitos diferentes do esperado, em virtude das interações entre constituintes químicos das plantas (Martins et al. 2000).

Para todas as plantas citadas, os informantes indicaram uma ou mais finalidades de uso terapêutico. As citações de usos foram agrupadas de forma mais geral, tomando-se como base o nome, o órgão afetado ou o sintoma da doença citada de acordo com a Classificação Internacional de Doenças (Organização Mundial de Saúde 2000).

O maior número de citações de doenças foi para o grupo de afeções relacionadas ao Sistema Digestivo (17\%) e ao Sistema Respiratório (17\%), assim como em outras regiões do interior paulista (A.P.G. Savassi, dados não publicados; M.C. Dias, dados não publicados; E.F.P.E. Gama, dados não publicados) e em outras localidades do Brasil (Amorozo 2002; Di Stasi et al. 2002; Garlet \& Irgang 2001; Amorozo \& Gély 1988). Em seguida, doenças do sistema genitourinário, relacionadas principalmente com os rins (pedra nos rins e "diurético"), e do sistema circulatório apresentam a mesma porcentagem (12\%). Doenças associadas com sintomas, sinais e achados anormais de exames clínicos e de laboratório não classificados em outra parte constituem $11 \%$ das citações. Neste grupo, incluem-se sinais relativos ao estado emocional e comportamental (nervosismo e depressão), além de sintomas gerais como dor de cabeça, febre e mal estar. Também tiveram $11 \%$ de citações, doenças relacionadas a lesões na pele, incluindo picadas de insetos e cuidados com os cabelos (Fig. 5).

De acordo com informações fornecidas pela enfermeira responsável pelo Posto de Saúde, as doenças mais freqüentes no distrito estão relacionadas com a falta de higiene e cuidados na preparação do alimento. Esta situação é propícia à incidência de distúrbios do sistema digestivo, como verminoses e dores de barriga, além de gripes e resfriados que são resultado da poeira e do organismo debilitado.

Tabela 1. Índices de diversidade e de eqüidade de Pielou de localidades com rica flora associada.

\begin{tabular}{lcccc}
\hline Local & H' Base e & e & Tipo principal de vegetação & Fonte \\
\hline Martim Francisco, SP, Brasil & 4,07 & 0,87 & Vegetação antropizada & Este trabalho \\
Santo Antonio do Leveger, MT, Brasil & 5,09 & 0,94 & Cerrado & Amorozo 2002 \\
Campo de refugiados de Phanatnikhom, & 4,97 & 0,99 & Floresta tropical & Pake apud Begossi \\
$\quad$ Tailândia & 5,24 & 0,94 & Floresta tropical & Amorozo 2002 \\
Barcarena, PA, Brasil & 5,2096 & Amoro \\
\hline
\end{tabular}




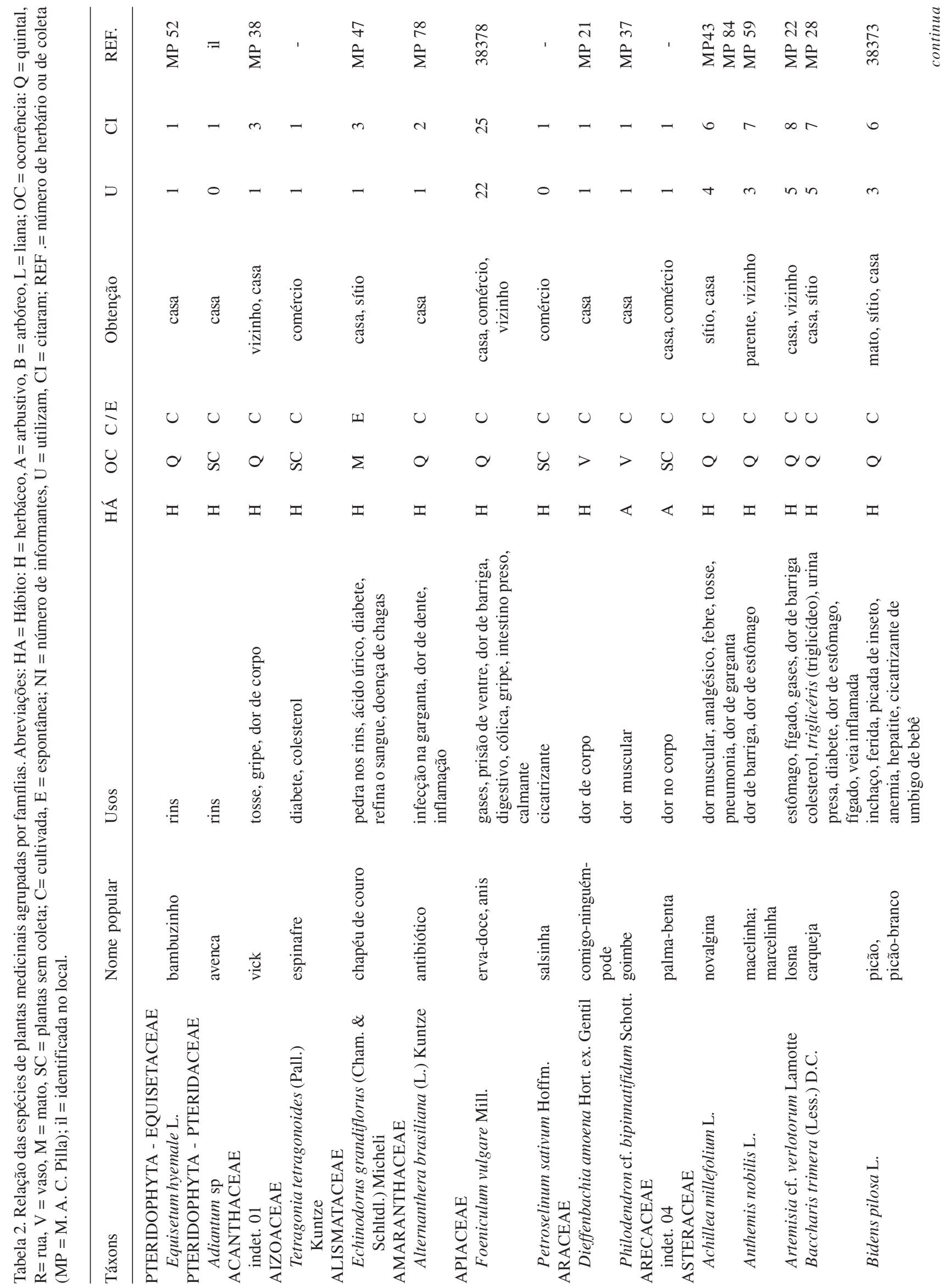




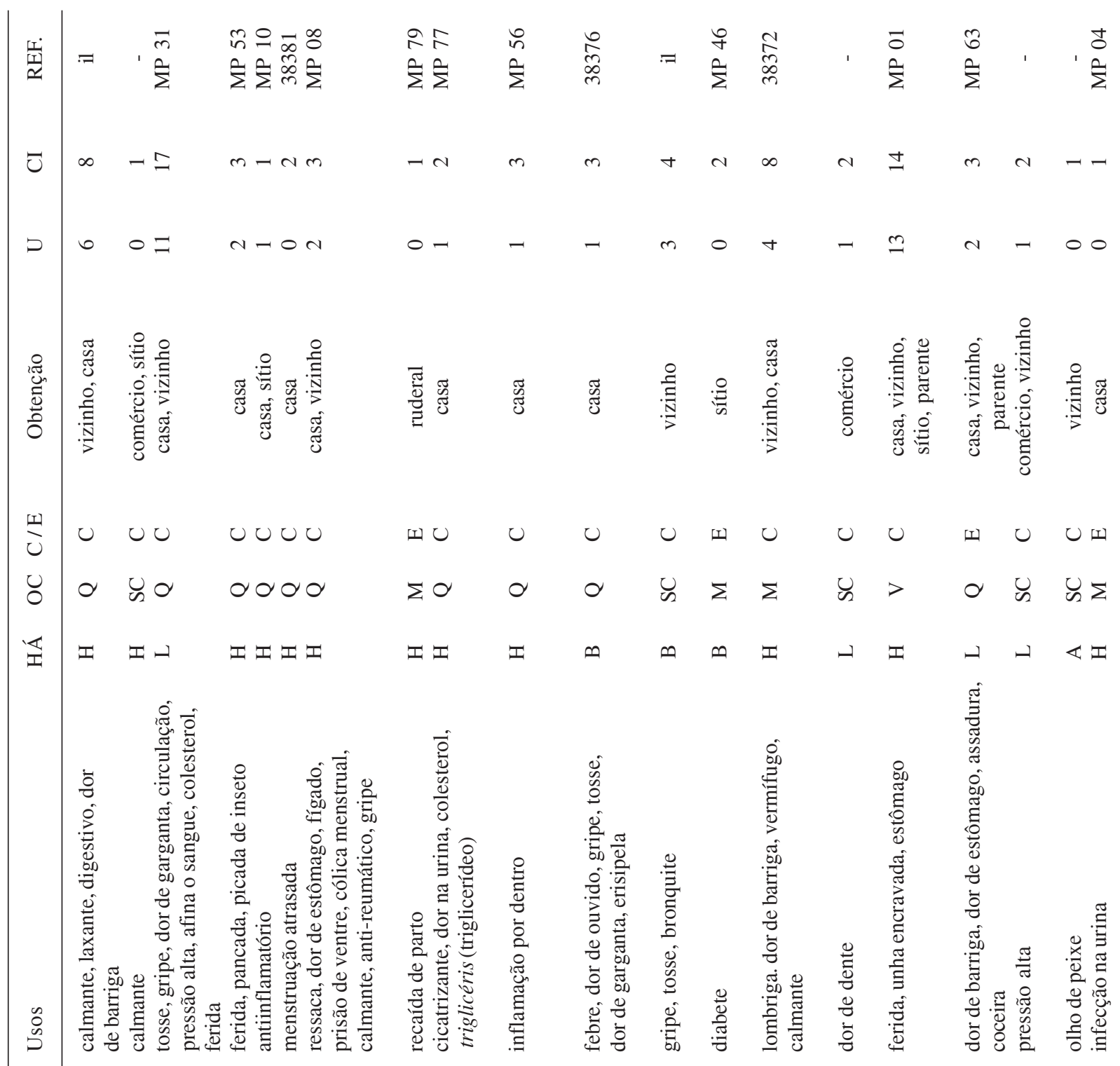

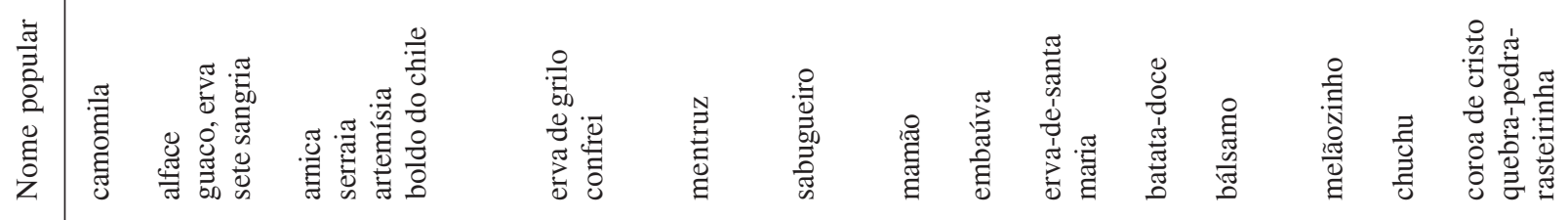

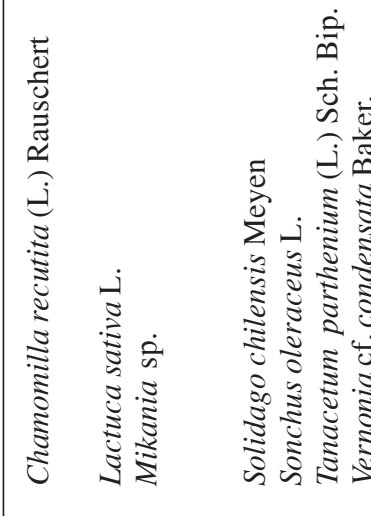
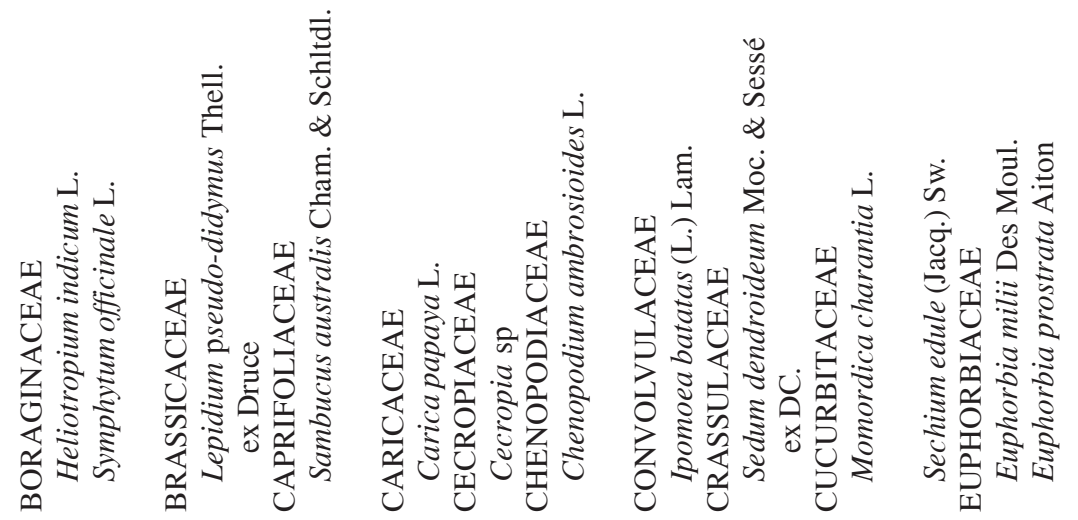


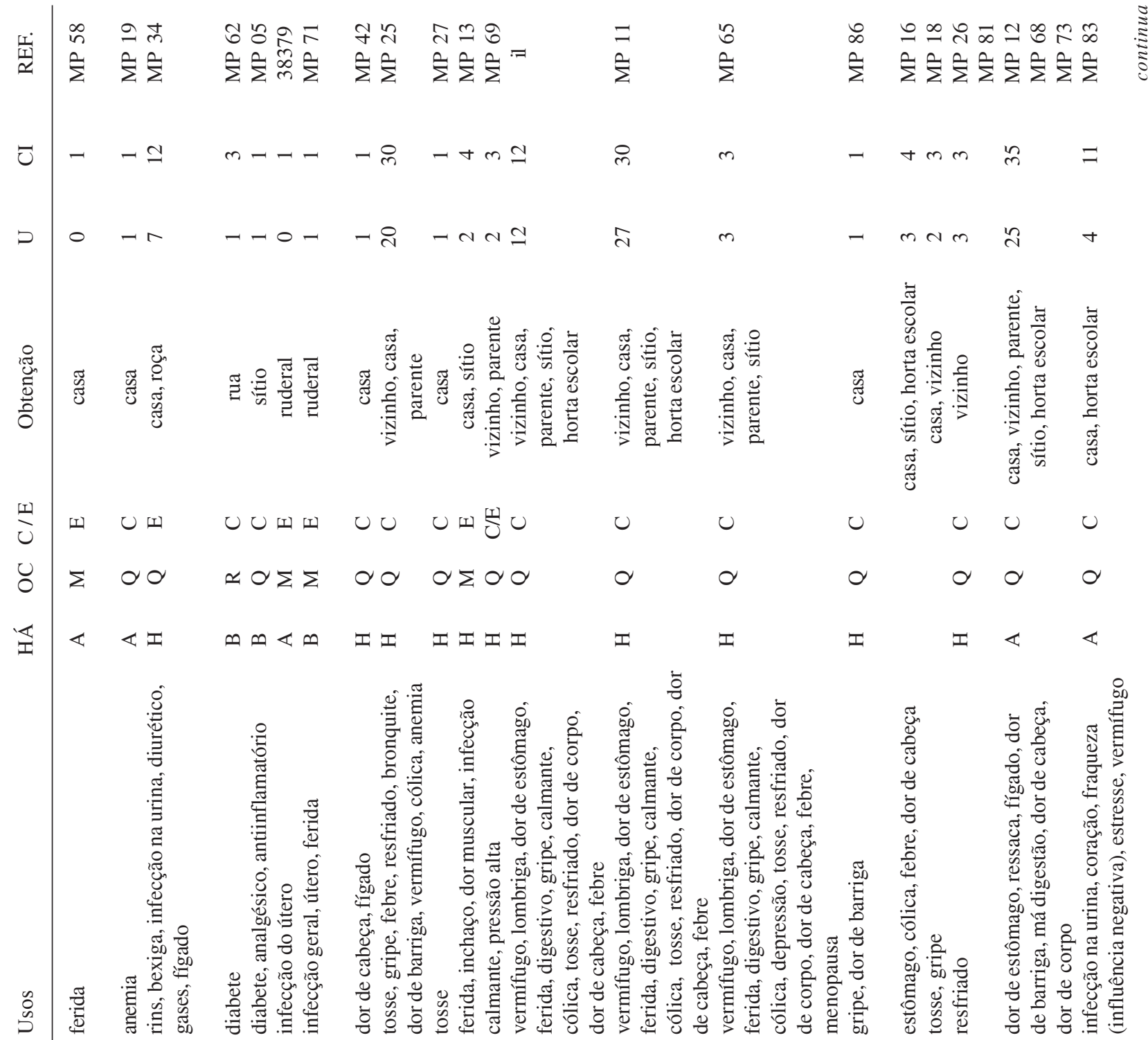

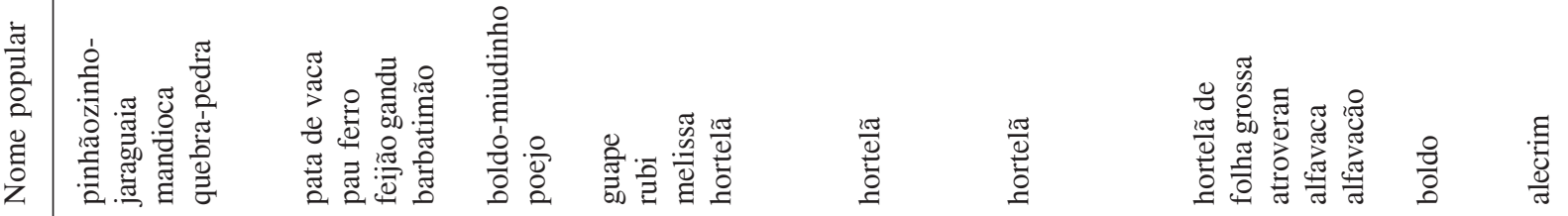




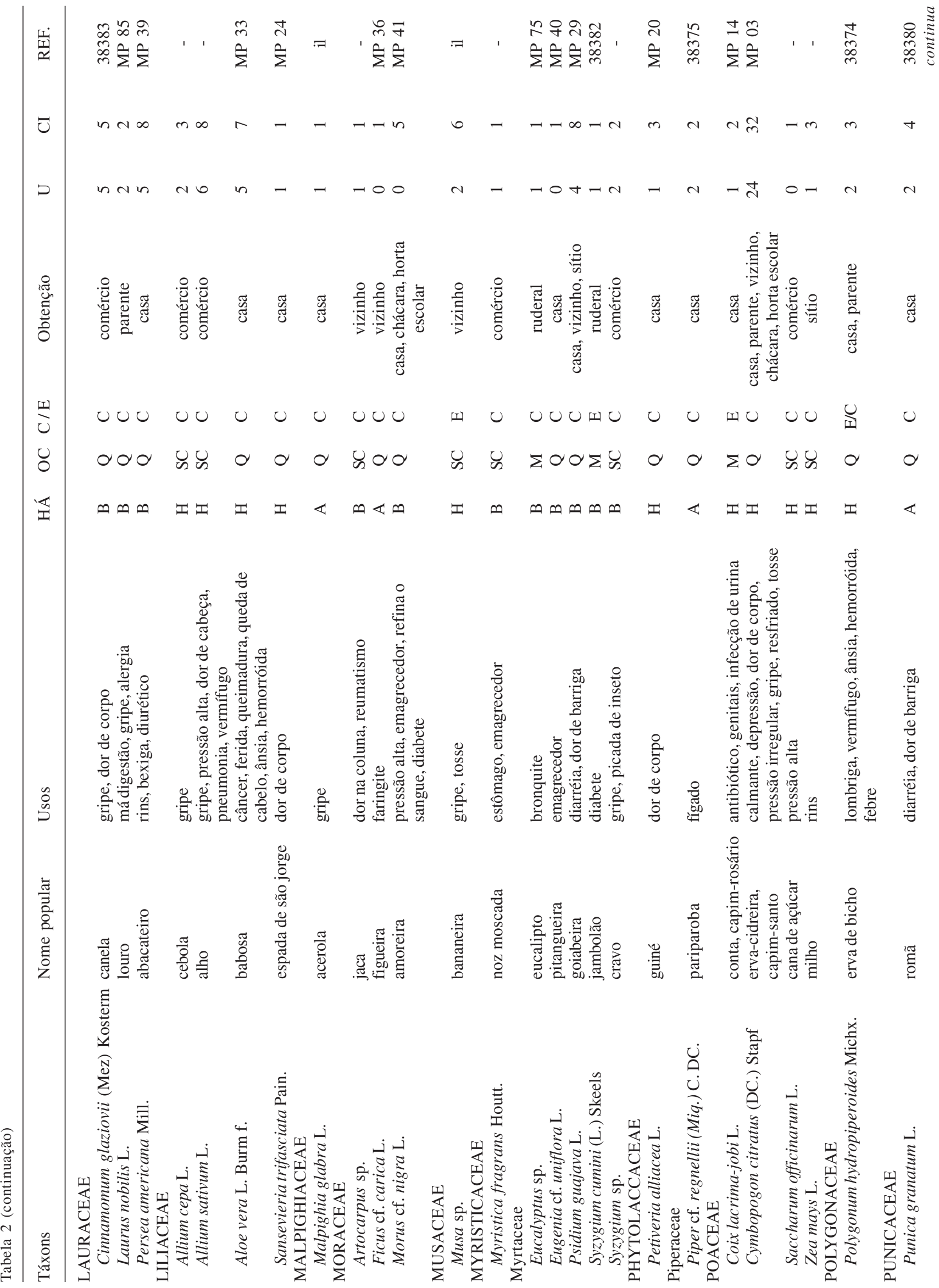




\begin{tabular}{|c|c|c|c|c|c|c|c|c|c|c|c|c|c|}
\hline$\frac{1}{\pi}$ & $\begin{array}{l}\bar{b} \\
\hat{\Sigma}\end{array}$ & $\begin{array}{l}\text { J } \\
\text { \& }\end{array}$ & ' & $\begin{array}{l}\hat{\lambda} \\
\dot{\Sigma}\end{array}$ & & \multicolumn{2}{|c|}{$\begin{array}{l}\hat{\delta} \infty \tilde{N} \\
\sum \hat{\Sigma} \tilde{\Sigma}\end{array}$} & $\begin{array}{l}\hat{o} \\
\hat{\Sigma}\end{array}$ & $\begin{array}{l}\frac{2}{2} \\
\sum\end{array}$ & $\begin{array}{l}8 \\
\dot{z}\end{array}$ & $\begin{array}{l}\stackrel{\infty}{+} \\
\stackrel{\rho}{z}\end{array}$ & $1 \quad 1$ & $\begin{array}{llll}1 & 1 & 1 & 1\end{array}$ \\
\hline 5 & $-m$ & $=$ & $a$ & -0 & $\neg \neg-$ & \pm & - & $\sim$ & - & $n$ & + & $\neg-0$ & $\rightarrow-m-\neg$ \\
\hline & $-N$ & 6 & + & $0+$ & 000 & $=$ & - & - & - & $m$ & $m$ & $00+0$ & 00000 \\
\hline 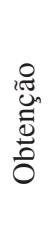 & 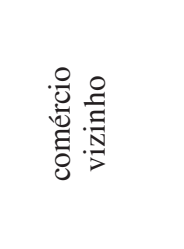 & 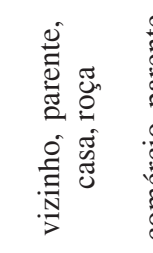 & 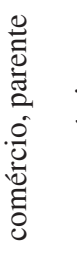 & 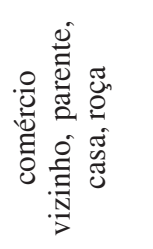 & 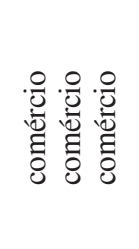 & 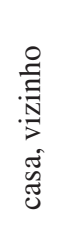 & 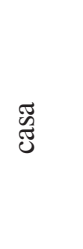 & שु & $\tilde{\mathscr{g}}$ & $\tilde{\tilde{~}}$ & 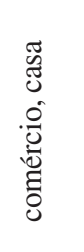 & 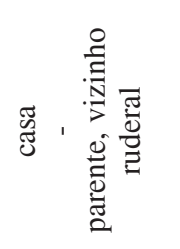 & , , , 1 , , \\
\hline & U & $U$ & $u$ & $\cup U$ & $\cup \cup U$ & J & $U$ & $U$ & $U$ & $U$ & $U$ & $\begin{array}{llll}1 & 1 & 1 & 1\end{array}$ & $\begin{array}{lllll}1 & 1 & 1 & 1 & 1\end{array}$ \\
\hline 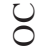 & U O & 0 & u & $U>$ & U Un & $\alpha$ & $\alpha$ & 0 & 0 & 0 & 0 & oUñ & U U U U U \\
\hline & $\infty \ll$ & $\infty$ & $\infty$ & $\sim \pm$ & $エ エ エ$ & $\varangle$ & ـ & $\dashv$ & $\dashv$ & $\Psi$ & I & 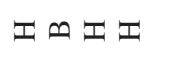 & ' 1 ' 1 ' \\
\hline $\begin{array}{l}n \\
0 \\
\infty \\
0\end{array}$ & 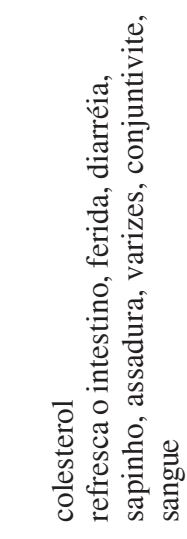 & 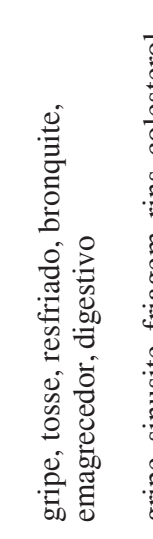 & 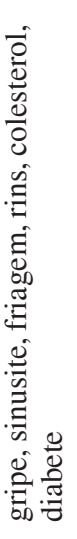 & 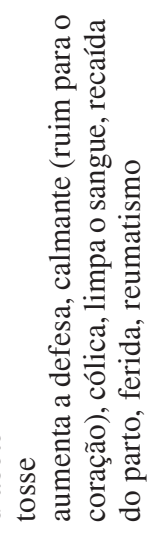 & 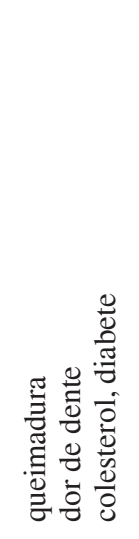 & 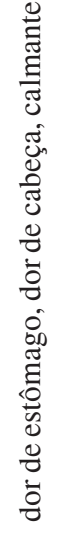 & 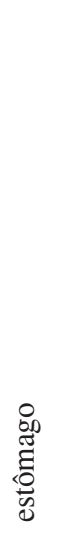 & 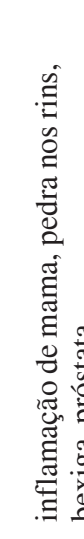 & 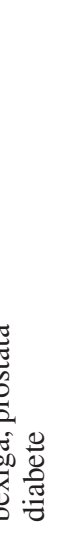 & 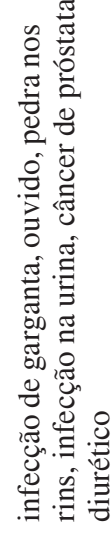 & 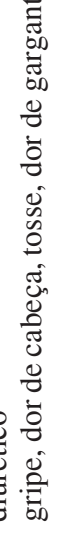 & 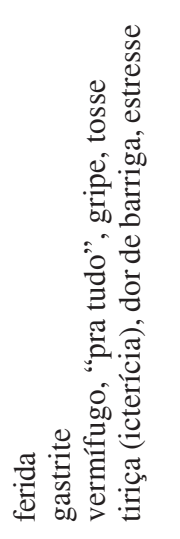 & 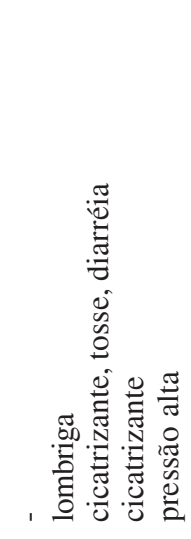 \\
\hline 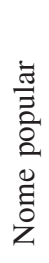 & 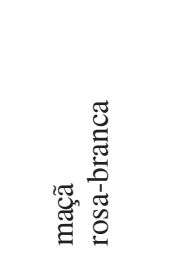 & 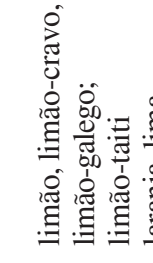 & 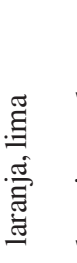 & 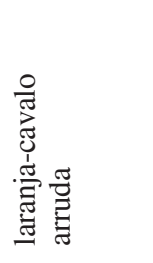 & 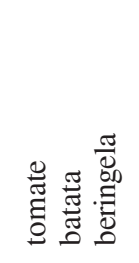 & 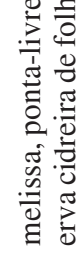 & 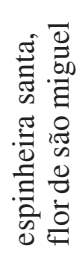 & 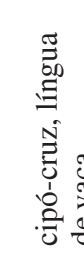 & 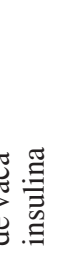 & 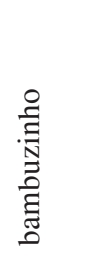 & $\begin{array}{l}0 \\
\stackrel{0}{5} \\
\bar{\varpi} \\
\overline{0}\end{array}$ & 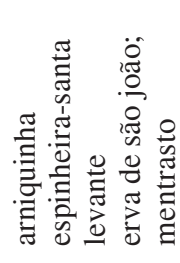 & 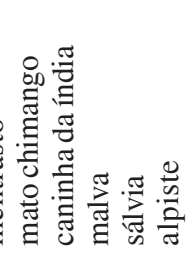 \\
\hline 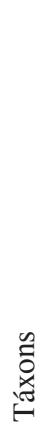 & 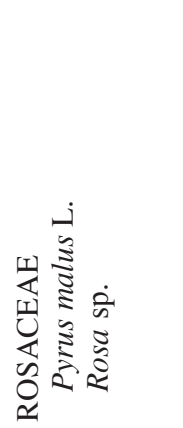 & 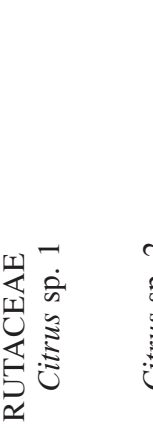 & $\begin{array}{l}n \\
\dot{2} \\
\text { ñ } \\
\text { है } \\
\text { : }\end{array}$ & 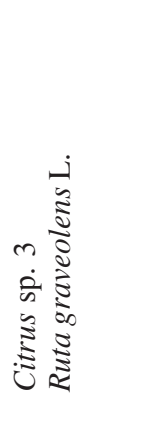 & 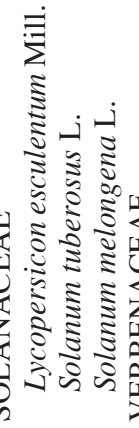 & 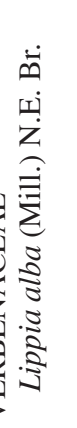 & 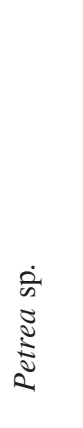 & 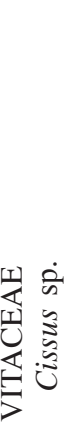 & 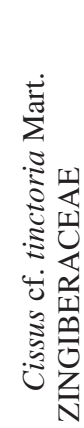 & 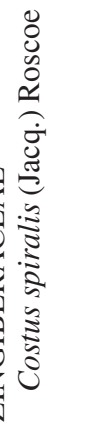 & 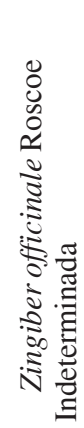 & 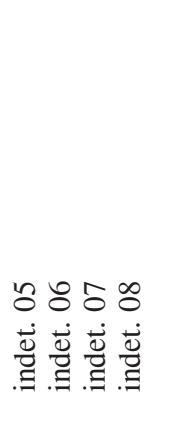 & 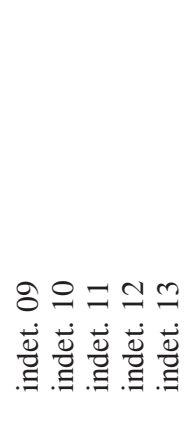 \\
\hline
\end{tabular}


Muitos informantes associaram o uso dos remédios caseiros, principalmente na forma de chá, com medicamentos industrializados. Desconfianças com relação à eficiência das propriedades de cura das plantas medicinais foram demonstradas apenas por poucos informantes. Essa restrição foi apresentada por indivíduos mais jovens, que procuram pelo médico principalmente para tratar de doenças de seus filhos. Este fato aponta para a tendência da população em procurar formas de tratamento terapêutico provenientes da medicina oficial.

Encontrou-se uma correlação positiva entre o número de plantas conhecidas e o número de plantas utilizadas pelos informantes (Kendall Tau $=0,6696$, $\mathrm{p}<0,0001$ ), o que demonstra que uma boa parte deste conhecimento é atualizada na prática. Do total de citações (516), 65,5\% referem-se ao uso efetivo pela população amostrada. Porém, houve diferença significativa entre o número de citações de plantas, tanto conhecidas como utilizadas, em relação ao grupo etário (Tab. 3). Indivíduos com 40 anos ou mais citaram, em média, cerca de $63 \%$ mais plantas medicinais conhecidas e $81 \%$ mais plantas utilizadas

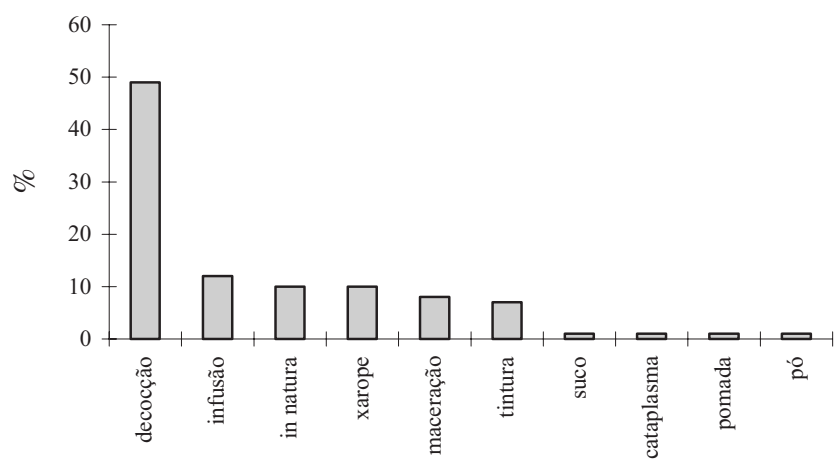

Figura 4. Formas de preparo dos remédios caseiros.

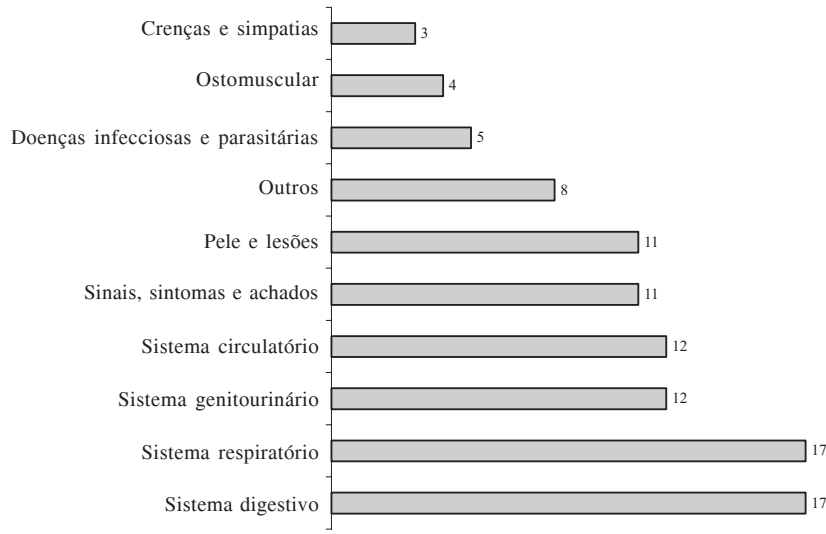

Figura 5. Citações por grupos de doenças (\%).
Tabela 3. Plantas conhecidas e utilizadas em diferentes grupos etários.

\begin{tabular}{lccccc}
\hline & \multicolumn{2}{c}{$\begin{array}{c}\text { Número e média } \\
\text { de citações }\end{array}$} & & \multicolumn{2}{c}{$\begin{array}{c}\text { Teste U de } \\
\text { Mann-Whitney }\end{array}$} \\
\cline { 2 - 3 } \cline { 5 - 6 } Citações & $\leq 39$ anos & $\geq 40$ anos & & Z ajustado & $\mathrm{p}$ \\
\hline Plantas conhecidas & $150(7,5)$ & $366(12,2)$ & $-3,078$ & 0,002 \\
Plantas utilizadas & $91(4,6)$ & $247(8,2)$ & & $-3,072$ & 0,002 \\
\hline
\end{tabular}

do que indivíduos com idade inferior a 40 anos. Também, durante as entrevistas, os indivíduos mais velhos da amostra demonstraram ser mais detalhistas nas informações sobre as plantas que utilizam. É interessante ressaltar que das 107 espécies obtidas, $76 \%$ tiveram pelo menos uma citação indicando uso ativo da planta.

A atribuição do nome de remédios industrializados ou de substâncias ativas a muitas plantas, tais como: vick (Acanthaceae), antibiótico (Alternanthera brasiliana), novalgina (Achillea milllefolium) e insulina (Cissus cf. tinctoria), demonstra a influência da medicina alopática no meio popular. Muitas vezes, os nomes dados a estas plantas fazem referência ao cheiro, gosto ou a um efeito de um remédio industrializado. Tal fato também foi relatado por Garlet \& Irgang (2001) no Rio Grande do Sul. Diferentes nomes foram dados à mesma planta, como por exemplo, em Santo Antonio do Leveger, MT, Amorozo (2002) encontrou Alternanthera brasiliana com a denominação de terramicina; no Rio Grande do Sul, esta mesma planta é denominada penicilina (Garlet \& Irgang 2001; Marodin \& Baptista 2001), ambos nomes de antibióticos conhecidos, o que é coerente com o emprego da planta. Quanto à posologia, não foi observado um rigor na quantidade a ser administrada. Boa parte dos usos de plantas é baseada na experiência, reforçando a idéia de que o que é natural não faz mal, o que é um equívoco. A grande maioria dos informantes não associou eventuais contra-indicações ao uso de remédios caseiros. Freqüentemente era dito: "é um santo remédio"; "se é da natureza não faz mal". Isto se deve à confiança nos produtos naturais e, de uma certa maneira, ao conhecimento empírico adquirido com os indivíduos mais idosos. De um modo geral, a dosagem não necessita ser administrada com rigorosa exatidão, porém muitas substâncias podem ser tóxicas se a dosagem for exagerada (Martins et al. 2000).

Importância relativa das espécies - Para verificar a 
Tabela. 4. Porcentagem de concordância quanto aos usos principais.(UP = usos principais; ICUE = número de informantes que citaram o uso da espécie; ICUP = número de informantes que citaram os usos principais; CUP = porcentagem de concordância quanto aos usos principais; FC = fator de correção; CUPc = CUP corrigida).

\begin{tabular}{|c|c|c|c|c|c|c|}
\hline Espécie & UP & ICUE & ICUP & CUP & $\mathrm{FC}$ & CUPc \\
\hline Plectranthus barbatus Andrews & dor de estômago e fígado & 35 & 32 & 91,4 & 1,00 & 91,4 \\
\hline Cymbopogon citratus (DC.) Stapf & calmante e pressão alta & 32 & 29 & 90,6 & 0,91 & 82,8 \\
\hline Mentha sp. 2 & vermes, dor de barriga & 30 & 27 & 90,0 & 0,86 & 77,1 \\
\hline Cunila microcephala Benth. & tosse, resfriado & 30 & 22 & 73,3 & 0,86 & 62,9 \\
\hline Foeniculum vulgare Mill. & dor de barriga (gases) & 25 & 17 & 68,0 & 0,71 & 48,6 \\
\hline Lippia alba (Mill.) N.E. Br. & calmante & 14 & 13 & 92,9 & 0,40 & 37,1 \\
\hline Mikania sp. & tosse, gripe & 17 & 13 & 76,5 & 0,49 & 37,1 \\
\hline Mentha sp. 1 & gripe, resfriado & 12 & 12 & 100,0 & 0,34 & 34,3 \\
\hline Phyllanthus corcovadensis Müll. Arg. & diurético, rins & 12 & 11 & 91,7 & 0,34 & 31,4 \\
\hline Sedum dendroideum Moc. \& Sessé ex DC. & ferida & 14 & 10 & 71,4 & 0,40 & 28,6 \\
\hline Citrus sp. 1 & gripe & 11 & 8 & 72,7 & 0,31 & 22,9 \\
\hline Psidium guajava $\mathrm{L}$. & diarréia & 8 & 8 & 100,0 & 0,23 & 22,9 \\
\hline Artemisia cf. verlotorum Lamotte & dor de barriga, fígado & 8 & 8 & 100,0 & 0,23 & 22,9 \\
\hline Ruta graveolens $\mathrm{L}$. & pós-parto & 10 & 8 & 80,0 & 0,29 & 22,9 \\
\hline Persea americana Mill. & diurético & 8 & 7 & 87,5 & 0,23 & 20,1 \\
\hline Chenopodium ambrosioides L. & dor de barriga e vermífugo & 8 & 7 & 87,5 & 0,23 & 20,1 \\
\hline Anthemis nobilis L. & dor de barriga, lombriga & 7 & 7 & 100,0 & 0,20 & 20,0 \\
\hline Musa sp. & gripe & 6 & 6 & 100,0 & 0,17 & 17,1 \\
\hline Achillea millefolium $\mathrm{L}$. & afeções do sistema respiratório & 6 & 6 & 100,0 & 0,17 & 17,1 \\
\hline Citrus sp. 2 & gripe & 9 & 6 & 66,7 & 0,26 & 17,7 \\
\hline Baccharis trimera (Less.) D.C. & colesterol, diabete & 7 & 5 & 71,4 & 0,20 & 14,3 \\
\hline Allium sativum $\mathrm{L}$. & gripe & 8 & 5 & 62,5 & 0,23 & 14,3 \\
\hline Costus spiralis (Jacq.) Roscoe & diurético & 5 & 5 & 100,0 & 0,14 & 14,3 \\
\hline Chamomilla recutita (L.) Rauschert & calmante & 8 & 5 & 62,5 & 0,23 & 14,3 \\
\hline Rosmarinus officinalis L. & sistema circulatório & 11 & 5 & 45,5 & 0,31 & 14,3 \\
\hline levante (indet. 07) & lombriga & 10 & 5 & 50,0 & 0,29 & 14,3 \\
\hline Aloe vera L. Burm f. & ferida, queda de cabelo & 7 & 4 & 57,1 & 0,20 & 11,4 \\
\hline Bidens pilosa $\mathrm{L}$. & ferida, picada de inseto, inchaço & 6 & 3 & 50,0 & 0,17 & 8,6 \\
\hline Morus cf. nigra L. & emagrecedor & 5 & 3 & 60,0 & 0,14 & 8,6 \\
\hline Cinnamomum glaziovii (Mez) Kostem & gripe & 5 & 2 & 40,0 & 0,14 & 5,7 \\
\hline
\end{tabular}

importância relativa das plantas utilizadas quanto ao número de informantes que citaram e à concordância dos usos citados, foram listadas as plantas mencionadas por cinco ou mais informantes, totalizando 30 plantas (Tab. 4). Várias plantas apresentaram forte consistência de uso (CUP de 100\%), como a hortelã (Mentha sp. 1), goiabeira (Psidium guajava), losna (Artemisia cf. verlotorum), macelinha (Anthemis nobilis), bananeira (Musa sp.), novalgina (Achillea millefolium) e bambuzinho (Costus spiralis). Porém, este valor decai para menos de $35 \%$ quando se aplica o fator de correção, comparando-as com a espécie mais citada, mostrando que seu conhecimento é restrito a poucos informantes. Nota-se que apenas quatro das 30 espécies mais citadas apresentaram CUPc acima de $60 \%$, correspondendo ao boldo (Plectranthus barbatus), ao capim-santo (Cymbopogon citratus), à hortelã (Mentha sp. 2) e ao poejo (Cunila microcephala).
Plectranthus barbatus foi a espécie mais citada pelos informantes e a que apresentou a mais alta concordância de uso (CUPc 91,4\%) principalmente para dores no estômago e fígado, este último associado à cura de ressaca.

O capim-santo ou erva-cidreira (Cymbopogon citratus), apresentou CUPc alta (82,8\%). Em outras localidades do interior paulista, os valores da CUPc desta planta foram superiores aos das demais. Em Ajapí, A.P.G. Savassi (dados não publicados) obteve $60 \%$ e em Ferraz, Silva-Almeida \& Amorozo (1998) obtiveram $80 \%$. Outros estudos também confirmam o uso desta planta como calmante e para pressão alta, tanto na região norte do país (Amorozo \& Gély 1988), quanto nas regiões sul e sudeste (Dorigoni et al. 2001; Garlet \& Irgang 2001; Castellucci et al. 2000; M.C. Dias, dados não publicados).

Friedman et al. (1986) sugerem que um bom critério para justificar o uso de uma planta é verificar 
a concordância de uso na comunidade. Quanto maior for esta concordância, é possível que a planta citada contenha algum composto químico que valide seu uso.

A utilização do boldo, para tratamento dos males do fígado e problemas de digestão, tem seu efeito comprovado por testes experimentais. Num ensaio farmacológico feito por Fischman et al. (1991), o extrato aquoso das folhas mostrou ação hipossecretora gástrica, o que faz diminuir a acidez e o volume da secreção do suco gástrico. Porém, ainda não se conhecem seus princípios ativos responsáveis por esta ação (Lorenzi \& Matos 2002). A análise fitoquímica registra a presença de barbatusina, ciclobarbatusina, cariocal, além de triterpenóides e esteróides (Kelecon \& Santos 1985; Zelnik et al. 1977). Estes constituintes podem ser utilizados para o controle de gastrite, dispepsia, azia, mal-estar gástrico, ressaca e como amargo estimulante da digestão e do apetite, porém, estudos que confirmem estes efeitos precisam ser realizados. Câmara et al. (2003) afirmam que o óleo essencial de Plectranthus barbatus tem efeito relaxante intestinal e atividade antiespasmódica e que a principal substância para estas ações parece ser o $\alpha$-pineno. Mesmo assim, os constituintes químicos identificados no óleo essencial não foram estudados completamente porque são inviáveis comercialmente e são muito difíceis de extrair em quantidades razoáveis para testes farmacológicos.

O chá da folha de Cymbopogon citratus utilizado como calmante e de ação espamolítica suave, tem sua composição química baseada em citral, que é um óleo essencial de atividade antimicrobiana, e mirceno que é o princípio ativo da ação analgésica (Lorenzi \& Matos 2002). Segundo Lorenzetti et al. (1991), o mirceno promove efeito analgésico direto de ação periférica, semelhante ao que é encontrado no ópio e dipirona. Diante deste dado, o uso popular do capim-santo ou erva-cidreira pode ser consistente para gripe, dores de cabeça e cólica devido à sua ação analgésica.

As espécies de Mentha, muito utilizadas para combater vermes intestinais, têm como principal componente o óleo essencial extraído das folhas, que é rico em mentol, mentona e mentofurano (Lorenzi \& Matos 2002). Porém, Santos et al. (1988) consideram essa planta como um vermífugo de baixo efeito.

Baseado nos dados é possível afirmar que a população de Martim Francisco ainda possui conhecimento e faz uso das plantas medicinais como uma das formas de tratar suas doenças mais freqüentes. Porém, quando se compara com sociedades tradicionais localizadas em regiões com rica flora nativa, os resultados obtidos no distrito não são tão expressivos. A perda da biodiversidade original contribui para o afastamento das pessoas do contato com a flora e desta forma as plantas usadas com fins terapêuticos passam a ser cada vez mais restritas a ambientes antropizados.

É importante ressaltar a predominância de plantas exóticas cultivadas nos quintais, pois uma grande porcentagem de espécies utilizadas como medicinais é introduzida. Neste estudo, as mais citadas para a cura de várias doenças foram o boldo (Plectranthus barbatus), o capim-santo (Cymbopogon citratus) e a hortelã (Mentha sp.), todas originárias do Velho Mundo, sendo o boldo nativo das regiões tropicais e úmidas da África e Ásia e a hortelã nativa da Europa e Ásia. O poejo (Cunila microcephala) também foi uma das espécies mais citadas, porém sua origem é brasileira. A única planta nativa de cerrado, o barbatimão (Dimorphandra sp.), foi citada por apenas um informante. Esta planta foi coletada em um ambiente bem alterado, próximo à linha férrea.

A maioria das plantas medicinais utilizadas é cultivada nos quintais das casas e trocada entre parentes e vizinhos. Este fato demonstra um certo grau de conservação das plantas e do conhecimento acerca dos seus usos, para o que o cultivo nos quintais mostrase essencial. No entanto, a diferença de conhecimento e uso de plantas medicinais entre os grupos etários foi estatisticamente significativa. Seriam necessários estudos mais aprofundados para avaliar se o grupo de idade mais jovem está em processo de aprendizado, e, eventualmente, alcançará o nível de conhecimento e utilização de plantas dos mais velhos, ou se está havendo um afastamento do conhecimento e uso de plantas medicinais pelos mais jovens.

Diante da alta incidência de doenças relacionadas à falta de higiene, tornam-se necessárias campanhas educativas para prevenção, além do estímulo à utilização segura dos fitoterápicos. Neste sentido, resgatar o conhecimento acerca de plantas medicinais pode contribuir na melhoria da qualidade de vida das pessoas desta comunidade, como um primeiro passo para a valorização e adequação dos recursos da medicina popular para o tratamento das doenças mais freqüentes.

\section{Agradecimentos}

À população de Martim Francisco, pela atenção, entusiasmo e colaboração para com a realização do trabalho; à FAPESP (processo 01/12455-5), pelo auxílio 
financeiro por meio da bolsa de iniciação científica; ao Prof. Dr. Silvio Govone, do Departamento de Estatística, Matemática Aplicada e Computação, IGCE, UNESP, Campus de Rio Claro, SP, pela assessoria estatística.

\section{Referências bibliográficas}

Amorozo, M.C.M. 2002. Uso e diversidade de plantas medicinais em Santo Antonio do Leveger, MT, Brasil. Acta Botanica Brasilica 16(2): 189-203.

Amorozo, M.C.M. \& Gély, A. 1988. Uso de plantas medicinais por caboclos do Baixo Amazonas, Barcarena, PA, Brasil. Boletim do Museu Paraense Emílio Goeldi, Série Botânica 4: 47-131.

Ayres, M.; Ayres Junior, M.; Ayres, D. L. \& Santos, A.S. 2006. BioEstat 4.0 Aplicações estatísticas nas áreas da ciências biológicas e médicas. Belém, Sociedade Civil Mamirauá/CNPq.

Begossi, A. 1996. Use of Ecological Methods in Ethnobotany: Diversity Índices. Economy Botany 50(3): 280-289.

Câmara, C.C.; Nascimento, N.R.F.; Macêdo Filho, C.L.; Almeida, F. \& Fonteles, M.C. 2003. Antispasmodic effect of the essential oil of Plectranthus barbatus and some major constituents on the Guinea-Pig ileum. Planta Medica 63: 1080-1085.

Castellucci, S.; Lima, M.I.S.; Nivaldo, N. \& Marques, G.W. 2000. Plantas medicinais relatadas pela comunidade residente na estação ecológica de Jataí, município de Luís Antônio/SP: uma abordagem Etnobotânica. Revista Brasileira de Plantas Medicinais 3(1): 51-60.

Di Stasi, L.C.; Oliveira, G.P.; Carvalhaes, M.A.; Queiroz Junior, M.; Tien, O.S.; Kakinami, S.H. \& Reis, M.S. 2002. Medicinal plants popularly used in the Brazilian Tropical Atlantic Forest. Fitoterapia 73: 69-91.

Dorigoni, P.A.; Ghedini, P.C.; Fróes, L.F.; Baptista, K.C.; Ethur, A.B.M.; Baldisserotto, B.; Burguer, M.E.; Almeida, C.E.; Lopes, A.M.V. \& Záchia, R.A. 2001. Levantamento de dados sobre plantas medicinais de uso popular no município de São João do Polêsine, RS - Relação entre enfermidades e espécies utilizadas. Revista Brasileira de Plantas Medicinais 4(1): 69-80.

Fischman, L.A.; Lapa, A.J.; Skoropa, L.A. \& Souccar, C. 1991. The water e extract od Coleus barbatus Benth. decrease gastric secretion in rats. Memórias do Instituto Oswaldo Cruz 86(supl. II): 141-143.

Friedman, J.; Yaniv, Z.; Dafni, A. \& Pale-Witch, D.A. 1986. A preliminary classification of the healing potential of medicinal plants, based on a rational analysis of an ethnopharmacological field survey among bedouins in the Negev desert, Israel. Journal of Ethnopharmacology 16: $275-287$.
Garlet, T.M.B. \& Irgang, B.E. 2001. Plantas medicinais utilizadas na medicina popular por mulheres trabalhadoras rurais de Cruz alta, Rio Grande do Sul, Brasil. Revista Brasileira de Plantas Medicinais 4(1): 9-18.

Hanazaki, N.; Tamashiro, J.Y.; Leitão Filho, H.F. \& Begossi, A. 2000. Diversity of plants uses in two Caiçaras communities from the Atlantic Forest coast, Brazil. Biodiversity and Conservation 9: 597-615.

IBGE. Censo demográfico 2000 - Sinopse preliminar. Disponível em: <http://www.ibge.gov.br/ibge/estatistica/ populacao/censo $2000 /$ sinopse.php?tipo $=21 \&$ paginaatual $=1 \& u f=35 \&$ letra $=m>$. (Acesso: $22 / 10 / 2001)$.

IBGE. Indicadores sociais mínimos: famílias por classes de rendimento médio mensal familiar - 1999. Rio de janeiro [2000]. Disponível em: <http://www.ibge.net>. (Acesso: 15/04/2003).

Kelecon, A. \& Santos, C. 1985. Cariocal, a new seco-abietane diterpene from the labiatae Coleus barbatus. Tetrahedron Letters 26: 3659-62.

Krebs, C.J. 1989. Pp. 654. Ecological Methodology. New York, Harper \& Row.

Lorenzetti, B.B.; Souza; G.E.P.; Sarti, S.J.; Santos Filho, D. \& Ferreira, S.H. 1991. Myrcene mimics the peripheral analsegic activity of lemongrass tea. Journal of Ethnopharmacology 34: 43-48.

Lorenzi, H. \& Matos, F.J.A. 2002. Pp. 512. Plantas medicinais no Brasil. Nova Odessa, Plantarum.

Marodin, S.M. \& Baptista, L.R.M. 2001.0 uso de plantas com fins medicinais no município de Dom Pedro de Alcântara, Rio Grande do Sul, Brasil. Revista Brasileira de Plantas Medicinais 4(1): 57-68.

Martin, G.J. 1995. Pp. 268. Ethnobotany -A 'People and Plants' conservation manual. London, Chapman \& Hall.

Martins, E.R.; Castro, D.M.; Castellani, D.C. \& Dias, J.E. 2000. Pp. 220. Plantas Medicinais. Viçosa, Editora UFV.

Organização Mundial de Saúde. 2000. Pp. 1191.CD-10: Classificação Estatística Internacional de doenças e problemas relacionados à saúde. São Paulo, Edusp.

Santos, C.A.M.; Torres, K.S. \& Leonart, R. 1988. Pp. 159. Plantas medicinais (Herbarim, flora et sciential). Curitiba, Scientia et labor.

Siegel, S. 1975. Pp. 350. Estatística não-paramétrica para as ciências do comportamento. São Paulo, Ed. MacGrawHill do Brasil.

Silva, A.J.R. \& Andrade, L.H.C. 2005. Etnobotânica nordestina: estudo comparativo da relação entre comunidades e vegetação na Zona do Litoral - Mata do Estado de Pernambuco, Brasil. Acta Botanica Brasilica 19(1): 45-60.

Silva-Almeida, M.F. \& Amorozo, M.C.M. 1998. Medicina Popular no Distrito de Ferraz, Município de Rio Claro, Estado de São Paulo. Brazilian Journal of Ecology 2: 36-46.

Zelnik, R.; Lavie, D.; Levy, E.C.; Wang, A.H.J. \& Iain, C.P. 1977. Barbatusin and ciclobutatusin, two novel diterpenoids from Coleus barbatus Bentham. Tetrahedron 33: 1457-67. 